Revista

Ibero-Americana

de Estratégıa

\title{
EXPANSÃO INTERNACIONAL PARA A CHINA E SEU REFLEXO NO AJUSTAMENTO INTERNACIONAL DO EXECUTIVO BRASILEIRO EXPATRIADO
}

\author{
BRAZILIAN INTERNATIONALIZATION STRATEGIES FOR CHINA AND THEIR \\ REFLECTIONS IN THE INTERCULTURAL ADJUSTMENT OF THE BRAZILIAN \\ EXPATRIATE INDIVIDUAL
}

\section{ESTRATEGIA DE INTERNACIONALIZACIÓN PARA CHINA Y SU REFLEJO EN EL AJUSTE INTERCULTURAL DEL INDIVIDUO BRASILEÑO EXPATRIADO}

\begin{abstract}
Aletéia de Moura Carpes
Mestranda em Administração pela Universidade Federal de Santa Maria - UFSM

E-mail: alecarpes.adm@ hotmail.com (Brasil)
\end{abstract}

\section{Flavia Luciane Scherer}

Doutora em Administração pela Universidade Federal de Minas Gerais - UFMG

Professora da Universidade Federal de Santa Maria - UFSM

E-mail: flaviascher@globo.com (Brasil)

\section{Daniel Diniz \\ Administrador de Empresas \\ E-mail: daniel@connectionmail.com (Brasil)}

\section{Thiago Antônio Beuron}

Mestrando em Administração pela Universidade Federal de Santa Maria - UFSM

E-mail: tbeuron@gmail.com (Brasil) 
Brasileiro Expatriado

\title{
EXPANSÃO INTERNACIONAL PARA A CHINA E SEU REFLEXO NO AJUSTAMENTO INTERNACIONAL DO EXECUTIVO BRASILEIRO EXPATRIADO
}

\section{RESUMO}

A busca estratégica por locais com maior vantagem de localização para o desenvolvimento das atividades fez com que algumas empresas do setor calçadista vislumbrassem na China um local favorável para fixação de fábricas e escritórios comerciais. A transferência das atividades para o território estrangeiro possibilita os benefícios inerentes à proximidade com o país escolhido, mas coloca em evidência o desafio de eleger, preparar as pessoas adequadas para a atuação internacional, além de realizar o acompanhamento do desenvolvimento do trabalho dos selecionados no exterior. Sabendo-se que o desempenho da empresa no exterior é influenciado pelo desempenho do indivíduo expatriado e que quanto maior for a diferença da cultura do país de origem com o país em que o indivíduo fixará domicílio, mais difícil é o ajustamento internacional do indivíduo, objetivou-se verificar empiricamente esta questão. Por meio do modelo de Black, Mendehall e Oddou (1991), foram exploradas as percepções de onze executivos brasileiros do ramo calçadista que com a expansão internacional passaram a trabalhar na China. Entre outras constatações, percebeu-se a ausência de orientações prévias vindas da empresa ao expatriado, o empecilho da distância psíquica no ajustamento do indivíduo e a postura reativa dos brasileiros como forma de se ajustar ao meio.

Palavras-chave: Ajustamento Intercultural; China; Expansão Internacional; Expatriado.

\section{BRAZILIAN INTERNATIONALIZATION STRATEGIES FOR CHINA AND THEIR REFLECTIONS IN THE INTERCULTURAL ADJUSTMENT OF THE BRAZILIAN EXPATRIATE INDIVIDUAL}

\begin{abstract}
The search for sites with greater strategic location advantage for the development of activities means that for some companies in the footwear sector, China represents a favorable site for the establishment of factories and commercial offices. The transfer of activities to foreign territory accords the inherent benefits of proximity to the chosen country, but highlights the challenges of choosing and preparing people for appropriate international action and following up on the development of selected work abroad. Business performance abroad is influenced by the performance of the individual expatriate, and the greater the difference of culture experienced between the country of origin and the country to which the individual will relocate, the lower the psychological comfort of the expatriate. Knowing this, this study's objective was to check the reflection of the internationalization of China in the individual expatriate intercultural adjustment, through the Black model, Mendehall and Oddou (1991). Among other findings, researchers noted the absence of advance directives coming from the expatriate company, the obstacle of psychic distance in the adjustment of the individual, and the reactive posture of Brazilians as a way of adjusting to the circumstance.
\end{abstract}

Keywords: Location Advantage; China; Expatriate; Adjustment.

Revista Ibero-Americana de Estratégia - RIAE, São Paulo, v. 10, n. 3, p. 22-48, set./dez. 2011. 
Aletéia de Moura Carpes, Flavia Luciane Scherer, Daniel Diniz \& Thiago Antônio Beuron

\section{ESTRATEGIA DE INTERNACIONALIZACIÓN PARA CHINA Y SU REFLEJO EN EL AJUSTE INTERCULTURAL DEL INDIVIDUO BRASILEÑO EXPATRIADO}

\section{RESUMEN}

La búsqueda estratégica por locales con mayor ventaja de localización para el desarrollo de las actividades hizo que algunas empresas del sector de calzados vislumbrasen en China un lugar favorable para fijar sus fábricas y oficinas comerciales. La transferencia de las actividades para el territorio extranjero posibilita los beneficios inherentes a la proximidad con el país escogido, pero pone en evidencia el desafío de elegir, preparar a las personas adecuadas para la actuación internacional y realizar la supervisión del desarrollo del trabajo de los seleccionados en el exterior. Dado que el desempeño de la empresa en el exterior es influenciado por el desempeño del individuo expatriado y que cuanto mayor sea la diferencia de la cultura vivida en el país de origen con el país en que el individuo fijará domicilio, menor será el confort psicológico del expatriado, se tuvo como objetivo verificar el reflejo de la internacionalización para China en el ajuste intercultural del individuo expatriado, por medio del modelo de Black, Mendehall y Oddou (1991). Entre las principales conclusiones, se notó la ausencia de orientaciones previas llegadas de la empresa al expatriado, la dificultad de la distancia psíquica en el ajuste del individuo y la postura reactiva de los brasileños como forma de ajustarse al medio.

Palabras-clave: Ventaja de Localización; China; Expatriado; Ajuste.

Revista Ibero-Americana de Estratégia - RIAE, São Paulo, v. 10, n. 3, p. 22-48, set./dez. 2011. 
Expansão Internacional para a China e seu Reflexo no Ajustamento Internacional do Executivo

Brasileiro Expatriado

\section{INTRODUÇÃO}

A busca estratégica por locais com maior vantagem de localização (Dunning, 1988) para o desenvolvimento das atividades fez com que algumas empresas do setor calçadista vislumbrassem na China um local favorável para fixação de fábricas e escritórios comerciais. Nesse contexto, observa-se a China como alvo da escolha estratégica de muitas nações, visto que desde a abertura comercial de 1978 ela cresce a uma média anual de 9\% e em 2002 destacou-se como o país que mais atrai investimento direto (De Góes, 2005), somando-se a esses atrativos a existência de milhões de pessoas compondo uma força de trabalho considerada mão de obra barata para os padrões internacionais.

Instalando-se na China, as empresas poderiam então se beneficiar das condições salariais do país, ter um grande mercado interno para o consumo de seus produtos (em 2008, a China foi a compradora de $85 \%$ da produção de calçados brasileiros para o mercado externo, mostrando-se um potencial destino dos produtos) (Abicalçados 2010) e baixos impostos para a instalação de suas fábricas, fatores associados que serviriam de pilares para a competitividade empresarial na arena global.

A transferência das atividades para o território estrangeiro possibilita os benefícios inerentes à proximidade com o país escolhido, mas coloca em evidência o desafio de eleger, preparar as pessoas adequadas para a atuação internacional, além de realizar o acompanhamento do desenvolvimento do trabalho dos selecionados no exterior. A expansão das atividades de uma empresa para territórios estrangeiros carrega a necessidade de que pessoas capacitadas operem as atividades, visando a otimização dos benefícios que a exploração do ambiente possibilita.

A essência da equipe de gestão de pessoas que atua em negócios globais estaria na capacidade de desvendar os talentos de indivíduos de valor que formam o capital humano (Moran, Harris e Stripp, 1996), já que "as pessoas são e serão cada vez mais o recurso precioso das organizações" (Lacombe, 2005 p.354).

Ao executivo que passa a trabalhar em uma unidade estrangeira da empresa dá-se o nome de expatriado e este desempenha um papel de grande importância para que a firma atinja o resultado desejado no ambiente internacional. Assim sendo, a performance da empresa no exterior é influenciada pelo desempenho do indivíduo expatriado e, como lembram Guiguet e Da Silva (2003), um indivíduo tende a obter melhor performance em função do quão ajustado estiver ao trabalho e aos cidadãos da nação hospedeira.

Revista Ibero-Americana de Estratégia - RIAE, São Paulo, v. 10, n. 3, p. 22-48, set./dez. 2011. 
O ajustamento internacional do expatriado seria fator preponderante ao satisfatório desenvolvimento das atividades internacionais da empresa e é definido por Ali (2003) como o grau de conforto do trabalhador no país hospedeiro. Como lembram De Paula e Staub (2005, p. 5), “um dos principais motivos de fracassos das expatriações é a falta de ajustamento do executivo no trabalho nas dimensões psicológica e sociocultural".

A dificuldade no ajustamento internacional do indivíduo seria proporcional a distância psíquica que a permeia: quanto maior a diferença cultural percebida pelo indivíduo na nova nação, mais difícil seria para ele interagir com as pessoas do novo país, amoldar-se nas novas atividades executadas e conviver com a cultura organizacional, aspectos estes que norteiam o ajustamento internacional (Black, Mendenhal e Oddou, 1991).

Kubo (2011) salienta a importância de pesquisas que contemplem o estudo do ajustamento internacional dos executivos e chama atenção para o fato de os trabalhos referentes a este assunto se deterem em medi-lo por meio do retorno prematuro do executivo ao país de origem, sendo escassas as pesquisas qualitativas que expliquem a forma que o expatriado se ajusta no exterior.

Observando esta lacuna, objetivou-se verificar como ocorreu o ajustamento internacional em executivos brasileiros que passaram a residir no território chinês após a inserção internacional de suas empresas no novo ambiente. Para alcançar o objetivo proposto, foram realizadas entrevistas semiestruturadas com onze executivos brasileiros que atuam no setor calçadista, sendo estes de diferentes empresas e níveis hierárquicos, observando a forma como estes indivíduos se ajustaram ao novo ambiente cultural, tão díspar do seu país de origem, de forma a desempenharem com eficácia os trabalhos aos quais foram designados.

A seguir, apresenta-se o panorama do setor calçadista do Brasil e as razões da inserção internacional para a China, seguido de considerações acerca da distância cultural que envolvem os negócios internacionais e da questão do ajustamento internacional do executivo. Tem-se a apresentação do método utilizado para o estudo proposto, os relatos advindos da sua aplicação e, por fim, as considerações finais do estudo.

Revista Ibero-Americana de Estratégia - RIAE, São Paulo, v. 10, n. 3, p. 22-48, set./dez. 2011. 
Expansão Internacional para a China e seu Reflexo no Ajustamento Internacional do Executivo

Brasileiro Expatriado

\section{O SETOR CALÇADISTA E A ESTRATÉGIA DE INTERNACIONALIZAÇÃO PARA A CHINA}

O parque brasileiro, hoje, contempla mais de seis mil indústrias de calçados, que produzem, aproximadamente, 650 milhões de pares/ano, distribuídos tanto para o mercado interno quanto para o exterior. A grande variedade de fornecedores de matéria-prima, máquinas e componentes, aliada à tecnologia de produtos e inovações, faz do setor calçadista brasileiro um dos mais importantes do mundo. São mais de 300 indústrias de componentes instaladas no Brasil, mais de 400 empresas especializadas no curtimento e acabamento do couro, processando anualmente mais de 30 milhões de peles (Aprendendo a exportar, 2010).

No entanto, desde o início de 2005, o setor vem enfrentando uma séria crise. Nos últimos anos, cresceram as dificuldades em decorrência, principalmente, da valorização excessiva do real frente ao dólar. Isso diminuiu a competitividade dos produtos brasileiros no mercado internacional e já provocou quedas nas exportações e no número de empregos.

Segundo a Associação Brasileira de Empresas de Componentes para Couro, Calçados e Artefatos (Assintecal), os motivos para a crise são os juros e a carga tributária elevados, o que resulta na queda da produção, fechamento de fábricas, demissões em massa e uma crise social e econômica generalizada. Outro agravante é que o setor suga os fornecedores mais importantes da cadeia produtiva: componentes e couro. De janeiro a outubro de 2005, o setor calçadista deixou de exportar 17,97 milhões de pares, que representam cerca de US\$ 178 milhões a menos no faturamento. Essa queda, que foi observada também no setor de couro, que, de acordo com a Associação das Indústrias de Curtume do Rio Grande do Sul (Aicsul), diminuiu em 18\% a produção (em volume físico) para exportação, também no acumulado até outubro, comparado com o mesmo período do ano passado.

Buscando uma alternativa de contornar a crise brasileira no setor, algumas empresas calçadistas do país optaram pela instalação de fábricas e escritórios na China, a maior exportadora e produtora mundial de calçados. De acordo com os entrevistados nesta pesquisa, a quantidade de mão de obra existente no país, aliada ao grande mercado de consumo interno e ao incentivo à entrada de Investimento Direto Externo (IDE), com impostos atraentes aos investidores estrangeiros, instigam a internacionalização ao mercado chinês.

A decisão estratégica da internacionalização para a China é alicerçada por Dunning (1988), que considera que as empresas possuem vantagens competitivas ou de propriedade vis-à-vis seus principais rivais e utilizam essas vantagens para estabelecer produção em locais que são atrativos devido a suas vantagens de localização.

Revista Ibero-Americana de Estratégia - RIAE, São Paulo, v. 10, n. 3, p. 22-48, set./dez. 2011. 
Este artigo propõe-se a verificar qual o reflexo desta escolha estratégica de internacionalização no ajustamento intercultural do indivíduo brasileiro expatriado que passa operar as atividades da empresa na China, país que oferece vantagens de localização para as firmas, mas que, devido a distância psíquica existente, pode afetar o ajustamento internacional do trabalhador.

\section{A INFLUÊNCIA DA DISTÂNCIA PSÍQUICA NO AJUSTAMENTO DO EXPATRIADO}

Estudos empíricos apontam que a afinidade cultural percebida pelo indivíduo está relacionada com a similaridade entre a cultura de origem e do país hospedeiro (Swift, 1999), sendo que a diversidade entre essas culturas causaria desconforto no indivíduo, de maneira a prejudicar o desempenho do trabalho e o fluxo de atividades exercidas, tamanha a distância psíquica existente. Compartilhando o mesmo ponto de vista, Homem $(2005$, p.4) lembra que "a distância cultural é negativamente relacionada com o ajustamento do expatriado".

Silva, Rocha e Figueiredo (2007) lembram que alguns trabalhos tratam a distância psíquica como sinônimo de distância cultural (Kogut e Singh, 1998; Lee, 1998), provavelmente devido a falta de desenvolvimento do conceito de distância psíquica entre os anos de 1980 e 1990. Por uma questão de aproximação, a distância cultural foi associada à distância psíquica, muitas vezes fazendo uso da escala de Hofstede (1980) para analisá-la.

Silva, Rocha e Figueiredo (2007), após realizarem uma discussão acerca das diferenças entre distância psíquica e cultural, defendem que esta seria componente integrante daquela e mais indicada para estudar grupos, e não o indivíduo (neste caso, o mais apropriado seria utilizar a distância psíquica). A distância psíquica, também chamada distância psicológica, foi definida internacionalmente a partir das seguintes descrições:

Figura 1- Autores e definições para a distância psíquica.

\begin{tabular}{|c|l|}
\hline AUTORES & DEFINIÇÃO DA DISTÂNCIA PSÍQUICA \\
\hline Beckman (1956) & $\begin{array}{l}\text { Distância percebida, relacionada à idioma, cultura } \\
\text { e contatos pessoais. }\end{array}$ \\
\hline Linnermann (1967) & $\begin{array}{l}\text { Percepções de risco, imperfeições nas informações } \\
\text { e barreiras culturais ao idioma. }\end{array}$ \\
\hline
\end{tabular}

Revista Ibero-Americana de Estratégia - RIAE, São Paulo, v. 10, n. 3, p. 22-48, set./dez. 2011. 
Expansão Internacional para a China e seu Reflexo no Ajustamento Internacional do Executivo

Brasileiro Expatriado

\begin{tabular}{|c|l|}
\hline Johanson e Wiedersheim-Paul (1975) & $\begin{array}{l}\text { Fatores que previnem ou perturbam os fluxos de } \\
\text { informação entre a firma e o mercado. }\end{array}$ \\
\hline Johanson e Vahlne (1977) & $\begin{array}{l}\text { Soma dos fatores prevenindo o fluxo das } \\
\text { informações de e para o mercado. }\end{array}$ \\
\hline O' Grady e Lane (1996) & $\begin{array}{l}\text { Grau de incerteza da firma sobre um mercado } \\
\text { externo resultante das diferenças culturais e outras } \\
\text { dificuldades comerciais que oferecem barreiras ao } \\
\text { aprendizado sobre o mercado e suas operações. }\end{array}$ \\
\hline Evans e Mavondo (2002) & $\begin{array}{l}\text { Distância entre o mercado local e o externo, } \\
\text { resultante da percepção tanto das diferenças } \\
\text { culturais quanto das diferenças de negócios. }\end{array}$ \\
\hline Baack e Baack (2006) & $\begin{array}{l}\text { União da distância nacional e da distância de } \\
\text { negócios, sendo processada pela experiência } \\
\text { individual. }\end{array}$ \\
\hline
\end{tabular}

Fonte: Elaborado pelos autores a partir de Weizmann (2007).

$\mathrm{Na}$ literatura de Negócios Internacionais, os estudos acerca da distância psíquica buscam verificar sua relação com as seguintes questões: escolha do modo de entrada no território estrangeiro (exportação direta ou indireta, franquia, subsidiária etc) (Johanson e Wiedersheim-Paul, 1975, Johanson e Vahlne, 1977), intensidade das transações da empresa com o país escolhido para as atividades (Linnermann, 1976, O’grady e Lane, 1996, Evans e Mavndo, 2002) e reflexo da distância psíquica no nível individual (Fletcher e Bohn, 1998; Baack e Baack, 2006). É sob esta última óptica que versa este artigo, já que se buscou apurar como ocorreu o ajustamento internacional dos indivíduos brasileiros que, com a inserção de suas empresas na China, passaram a residir em um novo ambiente, carregado por diferenças culturais, de idioma e organizacionais.

\section{O AJUSTAMENTO INTERNACIONAL DO INDIVÍDUO EXPATRIADO}

Cada localidade carrega suas peculiaridades, que, superficialmente, são visíveis nas comidas típicas, na forma de as pessoas se relacionarem entre si, além de outros hábitos e costumes, que causam, muitas vezes, um grande choque cultural ao indivíduo que é inserido no novo ambiente, além de dificultar o ajustamento do expatriado na nação hospedeira. Homem (2005) considera o 
ajustamento do expatriado como o resultado do processo de adaptação do indivíduo às demandas ambientais e Tung (1981) acredita que os bons resultados advindos de um processo de expatriação são consequência da habilidade do trabalhador em se ajustar à nova realidade.

De acordo com Selvarajah (2003), os expatriados experimentam certa quantidade de excitação, entusiasmo e ansiedade diante da perspectiva de irem a um novo ambiente. Segundo o autor, a disponibilidade ou a falta de informações influenciam as perspectivas pessoais dos expatriados desde o momento da decisão de mudança de país e as expectativas pré-embarque somadas com a experiência inicial no novo país também influenciam no seu ajustamento.

Conforme Sanchez, Spector e Cooper (2000), ao se deparar com uma nova cultura, o indivíduo sofre uma crise de identidade, com significativas transformações pessoais, já que deve reagir a um ambiente diferente do habitual. Como aponta Freitas (2000), viver em outro país significa construir outra vida, fazer novas representações e dar significados diferentes a aspectos que já eram familiares, gerando a reconstrução interna do indivíduo.

Em consonância, Homem e Tolfo (2004) salientam que a distância cultural é negativamente relacionada com o ajustamento do expatriado, ou seja, quanto maior for a diferença da cultura vivenciada no país de origem com o país em que o indivíduo fixará domicílio, menor será o conforto psicológico do expatriado.

Kubo (2011) verifica que muitas vezes o termo ajustamento é substituído por adaptação, sendo essas palavras utilizadas como sinônimo. No entanto, o autor salienta a diferença entre os dois termos, definindo que o ajustamento antecede a adaptação do indivíduo e traz a consideração de Winkelman (1994), que enfatiza que antes de se adaptar é necessário que o indivíduo se ajuste ao novo ambiente.

O insucesso no processo de ajustamento dos expatriados seria ocasionado pelas seguintes fatores, de acordo com Tung (1987), i) falta de ajustamento da família do expatriado; ii) falta de ajustamento do expatriado; iii) características pessoais do expatriado; iv) dificuldade do expatriado no trabalho assumido; v) insuficiente competência técnica; vi) falta de motivação para trabalhar no novo país e vii) outras questões familiares.

O ajustamento bem-sucedido do expatriado garantirá o desempenho satisfatório das atividades no exterior, e estaria relacionado com as características pessoais do profissional escolhido aliado ao suporte oferecido pela empresa antes e após a mudança de país (Bohlander, Snell e Sherman, 2005).

Selvarajah (2003), em pesquisa de natureza quantitativa com expatriados, constatou que estes indivíduos são influenciados por algumas variáveis, tais como quantidade de informações,

Revista Ibero-Americana de Estratégia - RIAE, São Paulo, v. 10, n. 3, p. 22-48, set./dez. 2011. 
Expansão Internacional para a China e seu Reflexo no Ajustamento Internacional do Executivo

Brasileiro Expatriado

conhecimento prévio do expatriado, perfil dos expatriados e experiências antes de ir ao país. Percebe-se então que novamente a díade características pessoais e suporte da empresa antes e após a mudança de país se faz presente, sendo também importante considerar o apontamento de Black, Mendenhall e Oddou (1991), que defendem que quando os trabalhadores são selecionados observando apenas suas competências técnicas, estes encontram dificuldade de ajustamento, pois este não ocorre sem a existência de competências interculturais.

Pereira, Pimentel e Kato (2005, p.60) lembram que "ao longo das últimas duas décadas, a questão do retorno prematuro de expatriados ao país de origem tem sido um problema recorrente e crescente pelos administradores de pessoal”, problemas estes relacionados aos altos custos em termos de desempenho gerencial, a produtividade nas operações do exterior, relação com clientes e eficiência operacional. Muritiba e Albuquerque (2009) consideram que o desafio da gestão de pessoas em empresas internacionalizadas envolve três aspectos: i) qualificação da força de trabalho; ii) aspectos culturais e iii) seleção e treinamento de expatriados, e lembram que um notório estudo de O'Sullivan, Appelbaum e Abikhzer (2002) mostrou que de 10 a $45 \%$ dos expatriados retornam ao país de origem antes do tempo previsto, pois encontram dificuldades de ajustamento no novo ambiente.

Apropriando-se da consideração de Ulrich (1998), acredita-se que a maior qualidade de uma empresa não se encontra em sua estrutura, mas no conjunto de talentos que integram sua equipe. Percebendo então a responsabilidade das equipes de gestão de pessoas em empresas internacionalizadas e a necessidade de suporte a estes diferenciais competitivos, verificou-se, por meio dessa pesquisa, por meio de relatos como ocorreu o processo de ajustamento internacional dos expatriados entrevistados.

\section{MÉTODO}

Pesquisas que possuem como foco países emergentes, tais como Brasil, Rússia, Índia, China e África do Sul têm sido contempladas em todas as partes do mundo e, conforme apontam Carpes et. al. (2010), são o $13^{\circ}$ tema mais publicado mundialmente na área de Negócios Internacionais, contando com 90.578 publicações entre 1997 e 2010. Observando que o estudo envolvendo países emergentes é de valia para a literatura acadêmica e verificando que a China tem sido estrategicamente escolhida por empresas brasileiras calçadistas para a instalação de escritórios e subsidiárias, optou-se por verificar como ocorre o ajustamento internacional do indivíduo que passa a residir no novo país, que, nesse caso, abriga uma grande distância psíquica.

Revista Ibero-Americana de Estratégia - RIAE, São Paulo, v. 10, n. 3, p. 22-48, set./dez. 2011. 
Percebendo a necessidade de pesquisas qualitativas que apresentem a forma como ocorreram os ajustamentos dos expatriados no ambiente internacional, foi realizado um estudo de natureza qualitativa com onze executivos brasileiros do setor calçadista que foram transferidos para a China no momento da inserção internacional da empresa. Os indivíduos possuem diferentes níveis hierárquicos e não pertencem a mesma empresa do setor calçadista.

Foram realizadas entrevistas semiestruturadas, que duraram cerca de quarenta minutos cada, entre os meses de abril e junho de 2010, com executivos escolhidos por conveniência. As entrevistas aconteceram em dias alternativos, de acordo com a disponibilidade do executivo expatriado, e foram realizadas na China, por questões de praticidade, visto que o entrevistador também reside neste país.

A via escolhida para serem obtidos os relatos a serem analisados foi o modelo de Black, Mendenhall e Oddou (1991), em que se verifica o ajustamento em duas etapas: antes do embarque ao país estrangeiro e durante a vivência na nova nação. O modelo de Black, Mendenhall e Oddou (1991) é referenciado como um dos mais completos para a verificação do ajustamento internacional de expatriados, sendo visto como universal pela literatura norte-americana (Kubo, 2011).

Os indivíduos que caracterizam a população deste estudo são os seguintes:

Figura 2- Perfil dos expatriados entrevistados.

\begin{tabular}{|c|c|c|c|c|c|}
\hline EXPATRIADO & SEXO & $\begin{array}{c}\text { IDADE } \\
\text { (ANOS) }\end{array}$ & $\begin{array}{c}\text { TEMPO QUE } \\
\text { TRABALHA COMO } \\
\text { EXPATRIADO }\end{array}$ & $\begin{array}{c}\text { CARGO NO } \\
\text { PAÍS DE } \\
\text { ORIGEM }\end{array}$ & $\begin{array}{c}\text { CARGO NO PAÍS } \\
\text { HOSPEDEIRO }\end{array}$ \\
\hline 1 & Masculino & 25 & 4 anos & $\begin{array}{c}\text { Desenvolvimento } \\
\text { de calçados }\end{array}$ & $\begin{array}{c}\text { Coordenador } \\
\text { comercial }\end{array}$ \\
\hline 2 & Masculino & 49 & 5 anos & $\begin{array}{c}\text { Analista de } \\
\text { negócios }\end{array}$ & $\begin{array}{c}\text { Analista de } \\
\text { negócios }\end{array}$ \\
\hline 3 & Masculino & 28 & 1 ano & $\begin{array}{c}\text { Auxiliar de } \\
\text { exportação }\end{array}$ & $\begin{array}{c}\text { Auxiliar de } \\
\text { exportação e } \\
\text { administração }\end{array}$ \\
\hline 4 & Feminino & 28 & 4 anos & $\begin{array}{c}\text { Assistente de } \\
\text { importação }\end{array}$ & $\begin{array}{c}\text { Gerente de } \\
\text { desenvolvimento e } \\
\text { produção }\end{array}$ \\
\hline 5 & Feminino & 38 & 2 anos & $\begin{array}{c}\text { Gerente comercial } \\
\text { e de produção }\end{array}$ & $\begin{array}{c}\text { Gerente comercial e } \\
\text { de produção }\end{array}$ \\
\hline
\end{tabular}

Revista Ibero-Americana de Estratégia - RIAE, São Paulo, v. 10, n. 3, p. 22-48, set./dez. 2011. 
Expansão Internacional para a China e seu Reflexo no Ajustamento Internacional do Executivo

Brasileiro Expatriado

\begin{tabular}{|c|c|c|c|c|c|}
\hline 6 & Masculino & 31 & 4 anos & Técnico em couro & $\begin{array}{c}\text { Supervisor de } \\
\text { materiais }\end{array}$ \\
\hline 7 & Feminino & 32 & 4 anos & $\begin{array}{c}\text { Gerente de } \\
\text { mercados }\end{array}$ & $\begin{array}{c}\text { Gerente } \\
\text { administrativa }\end{array}$ \\
\hline 8 & Masculino & 35 & 6 anos & $\begin{array}{c}\text { Agente } \\
\text { exportador }\end{array}$ & Agente exportador \\
\hline 9 & Masculino & 48 & 8 anos & $\begin{array}{c}\text { Técnico em } \\
\text { calçados }\end{array}$ & Gerente técnico \\
\hline 10 & Masculino & 44 & 10 anos & $\begin{array}{c}\text { Desenvolvimento } \\
\text { de calçados }\end{array}$ & $\begin{array}{c}\text { Gerente de } \\
\text { desenvolvimento }\end{array}$ \\
\hline 11 & Feminino & 35 & 9 anos & $\begin{array}{c}\text { Gerente comercial } \\
\text { Gerente de } \\
\text { exponhia de } \\
\text { calçados de }\end{array}$ \\
\hline
\end{tabular}

Fonte: Dados da pesquisa.

De acordo com Black, Mendenhall e Oddou (1991), o ajustamento do expatriado antes do embarque ao país estrangeiro estaria relacionado com as expectativas do indivíduo, que seriam formuladas de acordo com o treinamento proporcionado pela empresa para ele e com a experiência adquirida no desempenho das funções. Outros fatores que influenciariam o ajustamento do expatriado antes de fixar residência no exterior seriam os mecanismos e critérios da seleção utilizados pela empresa para a escolha do indivíduo que realizará a atividade internacional.

Já o ajustamento no país hospedeiro, de acordo com Black, Mendenhall e Oddou (1991), teria relação com os aspectos individuais (autoeficácia, habilidades de relacionamento e de percepção), no trabalho (clareza da função, autonomia da função, novidade da função e conflito na função), da cultura da organização (novidade da nova cultura - quanto maior a novidade, maior seria a dificuldade de ajustamento; suporte social - auxílio das pessoas que residem no país hospedeiro; ajuda logística- praticidade quanto a localização da moradia) e, ainda, a fatores que não estão relacionados ao trabalho: novidade da cultura e ajustamento da família do expatriado.

Segundo os autores, as esferas individual, trabalhista e da cultura organizacional encontram relação com o modo que será realizado o ajustamento e ao grau desse ajustamento no trabalho e nas interações em geral.

Revista Ibero-Americana de Estratégia - RIAE, São Paulo, v. 10, n. 3, p. 22-48, set./dez. 2011. 
Outro fator apontado por Black, Mendehall e Oddou (1991) no ajustamento no país hospedeiro é acerca da socialização organizacional, identificada pelas táticas de socialização e pelo conteúdo da socialização, realizadas com o intuito de integrar os membros da empresa. A socialização organizacional, de acordo com os autores, influenciaria o modo de ajustamento no exterior.

Os fatores descritos, referentes ao ajustamento antecipado e ao ajustamento no país hospedeiro, com suas relações de influência referentes ao grau de ajustamento, (representados pelos números nos parênteses) podem ser visualizados na Figura 3.

Figura 3- Modelo conceitual de ajustamento internacional.

Ajustamento antecipado

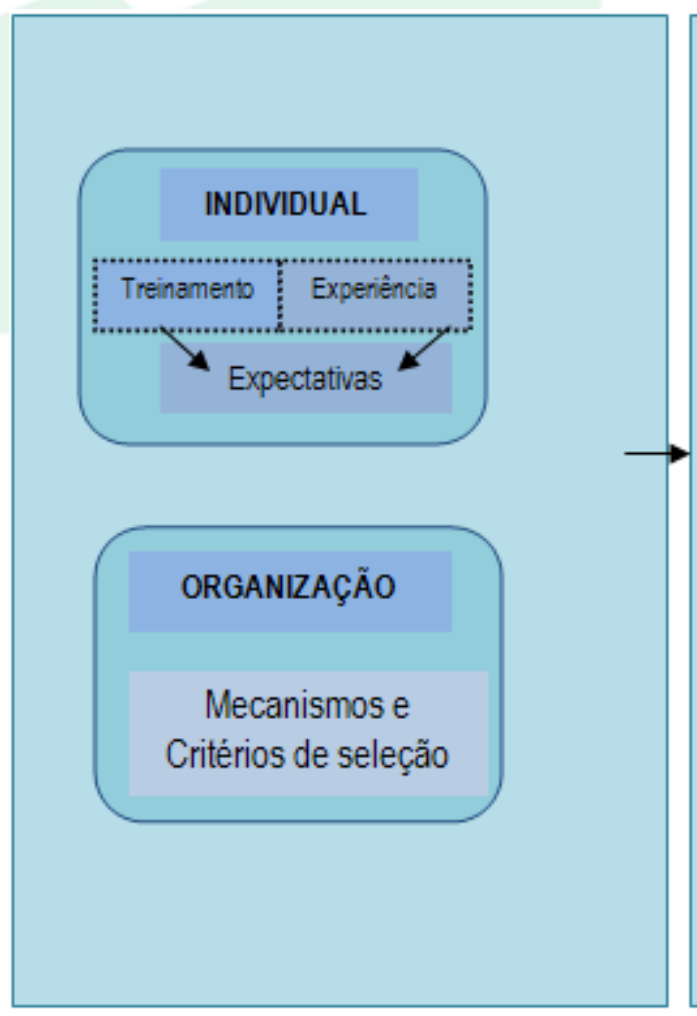

Fonte: Black, Mendenhal e Oddou (1991, p. 303).

\section{Ajustamento no país hospedeiro}

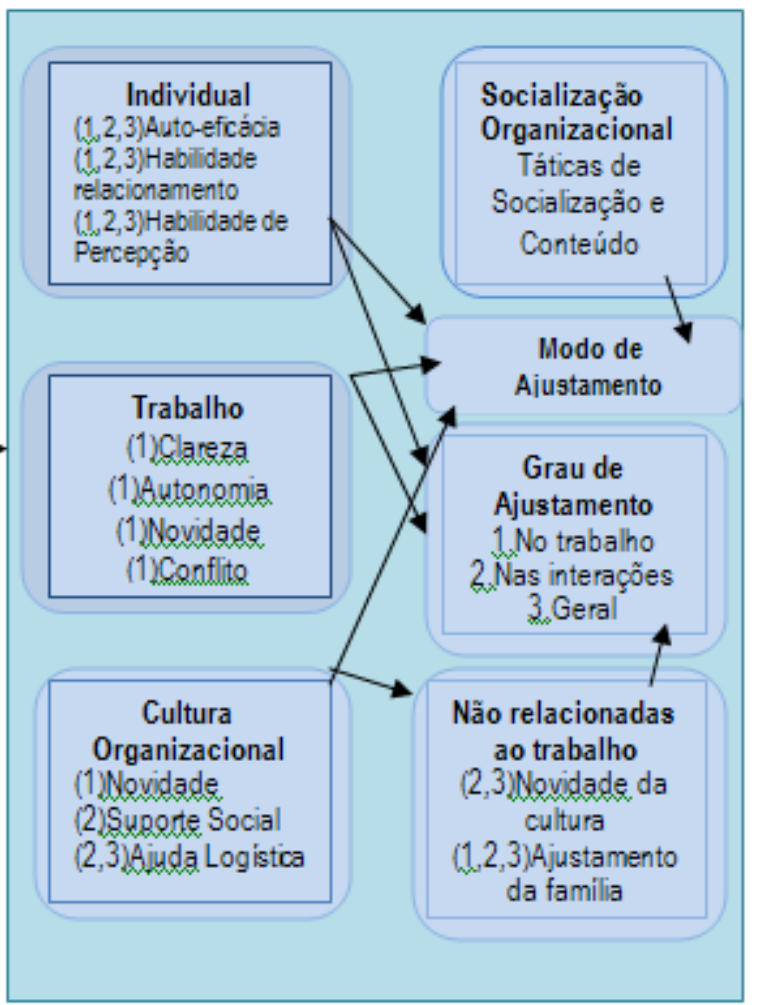


Expansão Internacional para a China e seu Reflexo no Ajustamento Internacional do Executivo

Brasileiro Expatriado

\section{APRESENTAÇÃO E DISCUSSÃO DOS RESULTADOS}

A partir do modelo de Black, Mendehall e Oddou (1991) e com a revisão da literatura apresentada nesse artigo, foram captados os relatos dos indivíduos expatriados, que apontam como ocorreu o processo de ajustamento internacional. A seguir, serão apresentados os aspectos de maior relevância para que seja atingido o objetivo proposto do artigo.

\subsection{AJUSTAMENTO ANTECIPADO}

Black, Mendehall e Oddou (1991) acreditam que o ajustamento internacional do expatriado inicia antes da mudança para o novo país, e que este é influenciado pelas expectativas formuladas pelo treinamento laboral e pela experiência prévia individual, além dos mecanismos e critérios de seleção realizados pela organização. Lessa et. al. (2008) apontam que a diferença entre o sucesso e o fracasso depende de como as organizações selecionam, treinam e gerenciam seus empregados para a atividade no exterior, cabendo à gestão de pessoas a incumbência de garantir que o executivo expatriado esteja apto a executar as funções da empresa em um país com diferenças culturais e iniciar outra etapa da vida, que inclui a distância dos familiares, nova moradia e estilo de vida.

De acordo com Black, Mendehall e Oddou (1991), indivíduos que receberam treinamento eficiente da empresa e que já conhecem a função que irão desempenhar no exterior têm maior facilidade de ajustamento internacional, portanto, as organizações devem observar estes critérios na escolha do funcionário a ser expatriado. Todos os expatriados entrevistados possuíam experiência prévia no setor calçadista e exerceram atividades similares no Brasil por, no mínimo, cinco anos, o que então seria um fator facilitador no ajustamento do indivíduo.

O executivo expatriado, ao ser alocado em outro país, irá iniciar uma nova etapa de sua vida pessoal e profissional, deparando-se com novos desafios em um ambiente desconhecido. As teorias de gestão de pessoas enfatizam que é de fundamental importância selecionar indivíduos capacitados para o desempenho das tarefas, sendo imprescindível prepará-los previamente para a atividade no exterior (Lacombe, 2005, Moran, Harris e Stripp, 1996).

E1: Não houve nenhum período de preparação para o país estrangeiro ou para o trabalho que eu iria desenvolver. [...] não diria que teria faltou algo específico, pois acredito que o que faz a grande diferença é como você irá se adaptar e encarar as diferenças culturais, depois de já ter chegado neste novo país e estar vivendo a realidade [...] o aprendizado se deu principalmente pelo interesse em aprender e ter a oportunidade de praticá-lo e também por um relacionamento com uma pessoa local.

Revista Ibero-Americana de Estratégia - RIAE, São Paulo, v. 10, n. 3, p. 22-48, set./dez. 2011. 
E2: Acho que foi boa a estratégia da empresa de passar as informações somente depois que desembarcamos no novo país. Você terá que vivenciar esta diferença cultural de qualquer forma, então não há muito que preparar previamente. Acredito que mesmo que não tenha havido um treinamento e orientações de cunho cultural, isso não fez falta posteriormente".

E5: Tive zero preparação. Como a expatriação aconteceu muito rápido, não tive tempo para me preparar pessoalmente e psicologicamente. Apenas tirei um tempo para fazer check-up de rotina, porque eu não tinha ideia do tipo de estrutura nessa área que iria me esperar na China. Na empresa, tive só uma reunião de menos de 2 horas explicando o básico.

E8: Não houve preparação e a minha ida para a empresa foi notificada somente com uma semana de antecedência, devido a uma situação de emergência na unidade da China. Tive então que usar minha experiência pessoal na função.Acho que o maior ponto de dificuldade foi a minha falta de conhecimento da legislação local, eu não tinha a menor ideia das leis sobre contratos e leis trabalhistas.

Apesar de as teorias apontarem para o treinamento e preparo adequado, os relatos coletados a partir das entrevistas indicaram que as equipes de gestão de pessoas não seguiram esta conduta. A maioria dos expatriados citou que a razão desta falta de preparo foi devido ao curto tempo entre a designação e a ida ao exterior.

Ainda que o retorno prematuro do expatriado seja uma questão preocupante em empresas que instalam escritórios ou subsidiárias no exterior (Pereira, Pimentel e Kato, 2005) e a principal razão da volta do indivíduo seja a falta de ajustamento no país (O’Sullivan, Appelbaum e Abikhzer, 2002), sendo então necessário suporte da firma ainda antes da mudança para o novo ambiente (Bohlander, Snell e Sherman, 2008), nota-se que as empresas do estudo não tiveram esta preocupação.

Bohlander, Snell e Sherman (2005) defendem que o ajustamento bem-sucedido do expatriado tem relação com as características pessoais do indivíduo e o suporte oferecido pela empresa. Como os expatriados 1, 2, 5 e 8 estão, respectivamente, há 4, 5, 2 e 6 anos trabalhando na China, acredita-se que o ajustamento de ambos foi satisfatório, e, neste caso, as características pessoais do expatriado superaram a necessidade de suporte por parte da empresa.

Chamou a atenção o fato de que grande parte dos expatriados acredita que o treinamento para a função e adaptação no país hospedeiro não teria relevância no desempenho satisfatório das atividades, que estaria, na verdade, relacionado à vivência das situações.

Revista Ibero-Americana de Estratégia - RIAE, São Paulo, v. 10, n. 3, p. 22-48, set./dez. 2011. 
Expansão Internacional para a China e seu Reflexo no Ajustamento Internacional do Executivo

Brasileiro Expatriado

\subsection{AJUSTAMENTO NO PAÍS HOSPEDEIRO}

Passada a fase do ajustamento antecipado, chegando ao país onde realizará as atividades laborais, o indivíduo expatriado deverá passar por uma adaptação gradual na nação anfitriã, assimilando os hábitos culturais e as maneiras adequadas para um bom convívio. Para Black, Mendehall e Oddou (1991), o ajustamento no país hospedeiro é reflexo dos planos individual, de trabalho, da cultura organizacional, da socialização organizacional e também de aspectos não relacionados ao trabalho.

Estes planos influenciariam no modo de ajustamento e no grau ou dimensão do ajustamento dos expatriados. Kubo (2011) lembra que Black, Mendehall e Oddou (1991) explicam que o modo de ajustamento do indivíduo pode ser reativo ou ativo, sendo a pessoa com este comportamento capaz de alterar o ambiente, de forma a adequá-lo às suas necessidades. Enquanto isso, o indivíduo com comportamento reativo faria o possível para se adequar ao ambiente. Abaixo, encontram-se os relatos considerados de maior relevância, organizados de acordo com o constructo correspondente.

\subsubsection{INDIVIDUAL}

A habilidade de o indivíduo ser autoeficaz, construir e manter relacionamentos no país hospedeiro e a capacidade de compreender o ambiente a sua volta seriam fatores importantes para o grau de ajustamento (no trabalho, nas interações e em aspectos gerais) e o modo com que esse indivíduo irá se ajustar (ativo ou reativo).

E1: Acredito que você sempre aceita entrar em uma nova empreitada com boas expectativas, sejam elas quais forem. Eu não tinha expectativas claras com relação ao país, povo, cultura, encontrei ali um caminho diferente, uma chance de mudar o rumo e "arriscar" um sucesso futuro, especialmente porque minha situação no país de origem não era muito interessante no momento. Eu me considero 100\% adaptado. Nas situações novas que surgem, eu encaro de forma bastante flexível.

E3: A adaptação é complicada e quase que impossível para pessoas que não têm a mente aberta, ampla e com poder de assimilar o "diferente", uma mente capaz de absorver as coisas boas e notar que não somente na nova pátria existem coisas ruins, mas onde anteriormente vivíamos também, é que pode entender que o nosso diferente é também diferente para o terceiro que ali vive.

Revista Ibero-Americana de Estratégia - RIAE, São Paulo, v. 10, n. 3, p. 22-48, set./dez. 2011. 
E5:A barreira da língua e costumes diários, alimentação e saúde ainda são muito difíceis de aguentar. Vivo em constante aprendizado e constante batalha de nervos, devido a barreira da linguagem, onde você se estressa até para pegar um táxi ou ir a um Mc Donalds, por exemplo. Aprendo a cada dia como administrar meu stress para não ser engolida por ele.

Como lembram Homem e Tolfo (2004), a distância cultural é negativamente relacionada com o ajustamento do expatriado, sendo a afinidade cultural percebida pelo indivíduo relacionada com a similaridade entre a cultura de origem e do país hospedeiro (Swift, 1999). O expatriado 5 aponta as dificuldades existentes devido a distância psíquica das duas nações, que estão presentes na língua, nos costumes diários, na alimentação e saúde, dizendo, inclusive, que diariamente precisa "administrar seu stress" para seguir sua rotina.

Retomando a ideia de Tung (1981), que acredita que os bons resultados advindos de um processo de expatriação são consequência da habilidade do trabalhador em se ajustar à nova realidade, percebe-se nos relatos dos expatriados 1, 3 e 5 a grande influência da vontade própria do indivíduo no grau de ajustamento no país anfitrião. Os indivíduos aceitaram a mudança de ambiente (e, como verificado do item 5.1, sem treinamento prévio e grande quantidade de informações que os auxiliassem na nova vida), por acreditarem que ela seria benéfica profissionalmente e então passaram a interagir com as dimensões do ambiente (trabalho, interações e outros aspectos gerais) de forma reativa.

\subsubsection{TRABALHO}

As características associadas ao trabalho desempenhado no país hospedeiro teriam relação com o modo e o grau de ajustamento internacional, sendo que a clareza e a autonomia da função elevariam o ajustamento, enquanto a novidade e o conflito da função o prejudicariam.

E1: O ritmo é muito mais pesado, de certa forma uma consequência, e anda em paralelo com a velocidade de evolução do país. Hoje em dia, em termos de carga horária, a diferença não é muito grande, mas o conteúdo e volume de atividades que você desenvolve são bem maiores. Tive um certo choque com relação a carga horária de trabalho bastante pesada e com as poucas opções de diversão. No entanto, eram apenas opções de diversão diferentes das que estava acostumado.

E4: O ritmo cansa um pouco, não há muito limite por parte das empresas sobre seu horário de folga, coisa que no Brasil é bem mais respeitado. Com certeza, aqui o volume de trabalho é bem maior, o

Revista Ibero-Americana de Estratégia - RIAE, São Paulo, v. 10, n. 3, p. 22-48, set./dez. 2011. 
Expansão Internacional para a China e seu Reflexo no Ajustamento Internacional do Executivo

Brasileiro Expatriado

ritmo de trabalho é mais intenso. As fábricas não param nos finais de semana, e você acaba trabalhando muito mais.

E8: Na China você está sempre envolvido com o trabalho. Mesmo que no final de semana as pessoas sempre ficam te ligando para discutir assuntos de trabalho. Outra coisa bem diferente é que aqui a gestão feita por eles é bastante retrógrada, o funcionário não participa das decisões, não é respeitado em sua função. Tudo é bastante formal.

Os relatos acima apontam que, apesar de os expatriados terem encontrado diferenças relacionadas ao exercício de seus trabalhos, eles souberam conduzir a nova realidade, assumindo uma postura reativa, na qual se adaptaram às exigências de seus serviços. Ainda, acredita-se que as similaridades das funções exercidas antes e após a expatriação tenham minimizado as dificuldades do ajustamento no trabalho.

\subsubsection{CULTURA ORGANIZACIONAL}

A novidade da cultura organizacional, o apoio oferecido pelas pessoas no país anfitrião e a praticidade dos aspectos referentes à localização e aos deslocamentos na nova nação facilitariam o ajustamento do expatriado e influenciariam no modo que ocorreria esse ajustamento.

Quanto menor a novidade da cultura, maior seria a facilidade do ajustamento do expatriado. Por meio dos relatos dos entrevistados, constatou-se a existência de diferenças de cultura organizacional nas empresas chinesas.

E1: Na China não se trabalha com muito planejamento, é imediato, resolvendo o problema que surge hoje e amanhã, e, às vezes, mudando de direção de uma semana para outra. Sem dúvida que o planejamento é importante, mas vivendo neste mundo globalizado de hoje, veloz e em constante metamorfose, ter esta habilidade de flexibilidade e de lidar com rápidas soluções é muito importante.

E3: Existe uma verticalização hierárquica muito forte, ou seja, a responsabilidade é sempre do funcionário em geral, porém, a última palavra, e o dono da verdade é sempre do chefe ou do diretor de nível hierárquico mais alto, o único e o principal da organização. Coisas que no Brasil se alinham muito mais descentralizadas.

Revista Ibero-Americana de Estratégia - RIAE, São Paulo, v. 10, n. 3, p. 22-48, set./dez. 2011. 
E4: É incrível como eles se submetem a um regime de trabalho de várias e várias horas diárias, sem reclamar. Acho que é mais porque eles não podem reclamar, mas mesmo assim, eles trabalham num ritmo que poucos aguentariam.

De acordo com Black, Mendenhall e Oddou (1991), as diferenças na cultura organizacional prejudicariam o ajustamento do expatriado no trabalho. Essas diferenças são visíveis no ambiente chinês, onde foram destacadas a falta de planejamento e a morosidade nas atividades, no entanto, percebe-se novamente a postura reativa dos indivíduos entrevistados, que compreendem as diferenças e se adaptam a elas.

O suporte social dos indivíduos do país hospedeiro ao expatriado também influenciaria positivamente no ajustamento, facilitando a aprendizagem dos hábitos vivenciados e das maneiras adequadas de convivência, refletindo de forma positiva na dimensão de ajustamento interacional. Foi constatada a existência de suporte social na maioria dos expatriados entrevistados, além de mais uma vez o modo de ajustamento ser reativo, pelo qual o indivíduo aprende e se ajusta ao meio onde vive.

E4: Os chineses são bastante receptivos, eles gostam de estrangeiros, porque para eles somos novidade. Faz pouco tempo que a China abriu suas fronteiras, então eles sempre querem saber sobre você, de onde você vem, como é a vida no seu país. E no trabalho também é assim, eles são bem prestativos.

E5: Meus amigos são basicamente outros estrangeiros expatriados e temos uma comunidade ativa. Não costumo andar muito com os expatriados do meu povo, pois quero aprender mais sobre outras culturas.Uma vez, sai com uma colega de trabalho que me deu a mão/abraçou (como se fosse um casal) enquanto passeávamos pela rua e eu fiquei assustada, não entendi o contato, daí ela viu que estranhei, ela riu e então fiquei sabendo que é normal por aqui.Não fico à vontade, mas como é normal acabo relevando.

A praticidade nos deslocamentos no novo país, incluindo a localização do trabalho, escolas e lojas de conveniência seriam outro fator auxiliar ao ajustamento internacional do indivíduo, nas dimensões interacional e geral, sendo constatado que na China o quesito da logística é considerado empecilho no ajustamento dos expatriados. Também, os indivíduos acabam adotando o modo de ajustamento reativo, fixando moradia nos locais que consideram mais práticos ou então buscando alternativas que facilitem o deslocamento.

Revista Ibero-Americana de Estratégia - RIAE, São Paulo, v. 10, n. 3, p. 22-48, set./dez. 2011. 
Expansão Internacional para a China e seu Reflexo no Ajustamento Internacional do Executivo

Brasileiro Expatriado

E9: Aqui na China é realmente uma loucura, as fábricas ficam muito afastadas do escritório. Às vezes, fico mais de duas horas no carro para chegar à fábrica. Aliás, uma das coisas que eu mais sinto falta do Brasil é o transporte público de fácil acesso.

E11: É bem complicada essa questão de deslocamento aqui na China, tudo é muito longe e essa cidade é muito grande. Mas, sinceramente, eu achava que seria muito pior, no entanto, a realidade que encontrei na China foi melhor do que a expectativa. Talvez por falta de mais informações, eu esperava um pais muito pobre, muito sujo, sem muita vegetação e com moradias precárias, sem escolas e supermercados de qualidade, até mesmo não esperava encontrar tantas opções. Além disso, esperava também que todo produto "Made in China" fosse de baixa qualidade. Entretanto, a realidade foi diferente.

\subsubsection{SOCIALIZAÇÃO ORGANIZACIONAL}

Para Black, Mendehall e Oddou (1991), a socialização organizacional não teria relação com as dimensões do ajustamento (trabalho, interacional e geral), mas com o modo do ajustamento (ativo ou reativo). Kubo (2011, p. 30) explica que a socialização organizacional representa "as táticas que as organizações utilizam para socializar os novos integrantes quanto aos comportamentos e perspectivas desejáveis no ambiente de trabalho".

E2: A empresa que eu trabalho nunca fez um tipo de socialização, e também não ouvi falar de algo parecido entre os muitos amigos brasileiros que tenho aqui e que também são expatriados. Acho que aqui tem essa velocidade de acompanhar o mundo todo e que daí influencia no ritmo acelerado. Todo mundo já chega na alta velocidade e tem que se virar para aprender sozinho, mesmo para aprender os hábitos, fazer amigos. Não é fácil porque é bem diferente de tudo que a gente vive no Brasil. Ajudaria muito se a empresa tivesse essa preocupação mesmo.

E9: A empresa que trabalho nunca teve essa preocupação de socializar os funcionários, acho que aqui na China isso acaba não acontecendo devido ao ritmo intenso de trabalho. O foco é no trabalho, cada minuto aqui é para isso, temos que acompanhar o ritmo ditado pelo país, pelo mundo. No meu ponto de vista, para os gestores daqui, isso seria perda de tempo, é mais para nós ocidentais, não tem tamanha importância na China.

Revista Ibero-Americana de Estratégia - RIAE, São Paulo, v. 10, n. 3, p. 22-48, set./dez. 2011. 
Todos os expatriados entrevistados disseram não ter existido a socialização organizacional vinda da empresa, mostrando uma lacuna neste suporte que a organização deveria proporcionar ao indivíduo. Os expatriados passam então a adotar uma postura ativa, buscando sozinhos a aprendizagem, e, conforme Black, Mendehall e Oddou (1991) e Kubo (2011) isso os torna inovadores nas suas funções, encorajando-os em relação as mudanças.

\subsubsection{NÃO RELACIONADO AO TRABALHO}

A novidade da cultura do novo país e o ajustamento da família do expatriado seriam refletidos no ajustamento satisfatório do indivíduo no exterior. A novidade da cultura influenciaria negativamente o ajustamento internacional nas dimensões do trabalho e da interatividade e esses apontamentos foram notórios nos relatos dos expatriados entrevistados.

E4: Certa vez exigi que uma funcionária de uma fábrica ficasse trabalhando comigo na hora do almoço. Eu ainda não tinha noção da importância desse horário para eles. E como ela fícou trabalhando, ela perdeu o horário do refeitório e a empresa não deixou ela almoçar depois, porque cada funcionário tem um horário. Depois que eu soube disso, eu tentei falar com o gerente dela para liberá-la pra comer, mas ele me disse que ela só poderia sair na janta. Eu vi que ela não ficou nada feliz comigo, depois disso, passei a respeitar esse horário.

E11: É um choque bastante grande entrar e viver na cultura chinesa. Quando sai do Brasil, tinha acesso a tudo: alimentação diversificada, transporte público de fácil acesso, e, principalmente, era possível conversar com qualquer um e ser entendido. Tudo isso mudou na China. Existe uma cultura da China moderna em formação. É fácil de entender, porém não quer dizer que seja fácil de conviver.

Black, Mendehall e Oddou (1991) consideram que o ajustamento da família teria um papel de importância no ajustamento do expatriado, influenciando as dimensões de trabalho, interacional e geral. De fato, essa afirmação foi mencionada pelos entrevistados como um fator que auxiliou no processo de ajustamento:

E2: Eu já havia tido experiência de trabalhar distante de casa (São Paulo e Paraíba), portanto acreditava que eu poderia me adaptar em mais esta circunstância. Com relação a meu filho, também imaginava que se adaptaria bem, o que de fato aconteceu. Tinha mais receio com relação a minha

Revista Ibero-Americana de Estratégia - RIAE, São Paulo, v. 10, n. 3, p. 22-48, set./dez. 2011. 
Expansão Internacional para a China e seu Reflexo no Ajustamento Internacional do Executivo

Brasileiro Expatriado

esposa, que não falava inglês, e eu também temia que ela não gostasse da cozinha chinesa, mas deu tudo certo e posso dizer que estamos muito bem, infiltrados. Queremos ficar aqui por mais outros anos.

E9: Eu vim antes para a China e a minha família só veio depois que eu estava completamente adaptado, senão certamente seria mais complicado. Conheci os hábitos, a cidade, aprendi a me virar no idioma para então passar para a família, então as coisas ficaram menos difíceis. Seria complicado eu passar quase o dia todo trabalhando e minha esposa ficar sozinha em um local totalmente desconhecido por nós dois. Por enquanto, a vida está tranquila, viemos porque a proposta de trabalho era absurdamente superior aos meus vencimentos no Brasil.

\section{CONSIDERAÇÕES FINAIS}

Verificando a inserção internacional das empresas calçadistas na China, devido a questões estratégicas, foi possível descrever como houve o ajustamento dos trabalhadores em um país considerado de grande distância psíquica, confrontando as orientações encontradas na literatura com a prática que foi vivenciada pelos indivíduos.

Neste caminho, percebeu-se que, embora a base teórica utilizada saliente que a equipe responsável pela Gestão Internacional de Pessoas deva estar atenta às necessidades prévias ao embarque do indivíduo para novo país, isto de fato não ocorreu com a maioria dos expatriados entrevistados. Muitos trabalhadores, tiveram um curto período entre a notícia da expatriação e a mudança de país, impossibilitando-os de um maior preparo psicológico, treinamento e recebimento de informações sobre a nova nação.

Foi percebida uma postura ativa da parte dos expatriados quanto à busca de informações e preparo para a atividade internacional, além de ter sido verificada a expectativa positiva da parte dos trabalhadores, que acreditavam poder encontrar no exterior uma possibilidade de crescimento profissional e até mesmo pessoal. Um fato que despertou atenção foi que os indivíduos não consideram importante um preparo mais criterioso por parte da empresa, acreditando que a maior aprendizagem virá na vivência no país, pois somente no dia a dia do novo ambiente poderiam ser sentidas as mudanças.

Analisando o processo de ajuste do expatriado já na nova nação, verificou-se que a questão de os trabalhadores entrevistados terem desempenhado funções similares que desempenhavam no 
Brasil auxiliou o ajustamento no trabalho e, embora tenham existido diferenças no ambiente das atividades, os indivíduos moldam-se às exigências. É válido salientar a presença da habilidade de percepção nos expatriados, que compreendem as divergências culturais (no país e na empresa) existentes e as consideram como forma de aprendizagem, conscientes que devem se ajustar a cultura do país, e não o contrário. A postura reativa, pela qual o indivíduo se ajusta ao meio, é inclusive o modo de ajustamento predominante entre os expatriados da pesquisa.

Ainda no ajustamento no país hospedeiro, foi encontrada outra lacuna referente às incumbências da equipe de Gestão de Pessoas, já que todos os entrevistados relataram a não ocorrência de uma socialização organizacional, momento em que a empresa deveria integrar os membros e expor aspectos referentes ao modo de trabalho, missão e visão. Foi percebida esta necessidade nos diálogos com os expatriados entrevistados, que evidenciaram essa carência, principalmente pela cultura daquele país ser bastante distinta da cultura brasileira. Corroborou-se a dificuldade para ajustamento internacional em país com grande distância psíquica, no entanto, os entrevistados acreditam que têm conseguido conviver com as diferenças, que, muitas vezes, são ensinadas por indivíduos nativos, com os quais formam laços de amizade.

Com esta pesquisa, verificou-se que a vontade própria do indivíduo de mudar de país e extrair dessa mudança benefícios pessoais, tais como ascensão profissional, melhor salário ou crescimento pessoal tem grande impacto no ajustamento internacional. Como, de acordo com a teoria, os pilares que sustentam o ajustamento eficaz do indivíduo seriam o apoio da empresa (antes e após a mudança para o país hospedeiro) e as características pessoais do funcionário, percebeu-se a relevância deste último na permanência do indivíduo em um país psiquicamente distante, visto que as empresas do estudo não proporcionaram o suporte adequado aos trabalhadores.

Este estudo também remete à consideração de Homem (2005), ao lembrar que os indivíduos que vivenciam no trabalho os reflexos da globalização devem ser "sem fronteiras", flexíveis e receptivos à mudança, ajustando-se de acordo com as transformações do ambiente global. Para as empresas pesquisadas, a China foi considerada um país atraente para o exercício das atividades devido a baixa taxa de impostos, grande mercado interno e abundante mão de obra a pequenos custos, e então os funcionários das empresas tiveram que ser receptivos à mudança para viverem uma nova vida em um ambiente totalmente diferente, mas onde era possível usufruir de benefícios buscados pelas empresas. Conforme lembra Lacombe (2005), uma das qualidades mais importantes para qualquer profissional é sua capacidade de adaptação, já que as técnicas e os conceitos mudam várias vezes ao longo de uma vida profissional.

Revista Ibero-Americana de Estratégia - RIAE, São Paulo, v. 10, n. 3, p. 22-48, set./dez. 2011. 
Expansão Internacional para a China e seu Reflexo no Ajustamento Internacional do Executivo

Brasileiro Expatriado

Por fim, sugerem-se novas pesquisas acadêmicas de natureza qualitativa que contemplem o ajustamento internacional do indivíduo, buscando dados com expatriados de outros países a fim de possibilitar a comparação do processo em diferentes culturas. Também, tornam-se relevantes estudos que tragam exemplos de sucesso da Gestão Internacional de Pessoas quanto à preparaçãotreinamento pré-expatriação, bem como de acompanhamento do indivíduo no país anfitrião.

\section{REFERÊNCIAS}

Abicalçados (2010) Dados do setor calçadista. Recuperado em 27 nov.2010, de http: // www.sindicalcados-es.com.br/Informa.doc>

Ali, A. J.(2003) Intercultural Adaptation Among Expatriates Spouses and Children, Tese (Doutorado). Universidade de Groningen, Holanda.

Aprendendo a exportar. Sobre o setor: calçados. Recuperado em 07 jun.2010, de http://www.aprendendoaexportar.gov.br/calcados/frameset_setor_historico.htm.

Baack, D. W., Baack, D. (2006) Psychic distance: a conceptual framework. Proceeding of the Annual Meeting of the Association of Collegiate Marketing Educators.

Beckerman, W. (1956) Distance and the pattern of intra-european trade. The Review of Economics and Statistics, 28.

http://dx.doi.org/10.2307/258863

http://dx.doi.org/10.5465/AMR.1991.4278938

Black, J.S., Mendenhall, M., e Oddou, G. (1991) Toward a comprehensive model of international adjustment: an integration of multiple theoretical perspectives. Academy of Management Review, 291-317.

Carpes, A.M., Velter, A.N., Scherer, F.L., Lütz, C.B. (2010) Panorama internacional das publicações em international business: levantamento através da base web of science. Internext, $5(2$.

De Góes, B.B. (2006) Expansão internacional para a china: estudo de caso de uma empresa brasileira. Dissertação (Mestrado). Universidade Federal do Rio de Janeiro, Rio de Janeiro.

De Paula, E.R., Staub, I.D. (2005) A mineiridade sob o olhar dos executivos expatriados italianos. In: Anais do Encontro da ANPAD, 29 Brasília.

Revista Ibero-Americana de Estratégia - RIAE, São Paulo, v. 10, n. 3, p. 22-48, set./dez. 2011. 
Dunning, J.H. (1988) The eclectic paradigm of international production: a restatement and some possible extensions. Journal of International Business Studies, 19(1).

http://dx.doi.org/10.1057/palgrave.jibs.8490372

Evans, J., Mavondo, F.(2002) Psychic distance: the construct and measures. American Marketing Association, 308 - 314.

Guiguet, J.M.S., Da Silva, J.R.G. (2003) O processo de adaptação dos expatriados e a importância relativa dos aspectos socioculturais. In: Anais do Encontro da ANPAD, 27, São Paulo, 2003.

Homem, I.D., Tolfo, S.R. (2004) Gestão intercultural: perspectivas para o ajustamento de executivos expatriados. In: Anais do Encontro da ANPAD, 28, Curitiba, 2004.

Homem, I.D. (2005) O ajustamento intercultural de expatriados: um estudo de caso em uma multinacional brasileira do Estado de Santa Catarina. In: Anais do Encontro da ANPAD, 29, São Paulo, 2005.

Johanson, J., Wiedersheim-Paul, F. (1975) The internationalization of the firm: four Swedish cases. Journal of Management Studies, 12(3), 305-322.

http://dx.doi.org/10.1111/j.1467-6486.1975.tb00514.x

Johanson, J., Vahlne, J.E.(1977) The internationalization process of the firm: a model of knowledge development and increasing foreign market commitments. Journal of International Business Studies, 8(1), 23-32.

http://dx.doi.org/10.1057/palgrave.jibs.8490676

Kubo, E.K.M.(2011) Ajustamento intercultural de executivos expatriados no Brasil. Tese (Doutorado). Fundação Getúlio Vargas, São Paulo.

Lacombe, F. J.(2005) Recursos humanos: princípios e tendências. São Paulo, Editora Saraiva.

Lessa, L.C.C.; Teixeira, L.A.A,; França Filho, G.G. De; Roque, L.M.(2008) Executivos brasileiros expatriados: percepções da nova função e influência da distância psíquica. In: Anais do XXXII Encontro da ANPAD, 32, Rio de Janeiro.

Linnemann, H. (1967) The plan that failed : the united nations development decade and beyond. Institute of Social Studies (ISS). Haarlem : Bohn.

Moran, R. T., Harris, P. R., Stripp, W. G. Desenvolvendo organizações globais. São Paulo: Makron Books do Brasil, 1996.

Muritiba, P.M., Albuquerque, L.G.(2009) Características da gestão estratégica de pessoas para as organizações internacionais. In: Albuquerque, L.G., Leite, N.P.(Org.) Gestão de pessoas: perspectivas estratégicas.São Paulo, Atlas.

Revista Ibero-Americana de Estratégia - RIAE, São Paulo, v. 10, n. 3, p. 22-48, set./dez. 2011. 
Expansão Internacional para a China e seu Reflexo no Ajustamento Internacional do Executivo

Brasileiro Expatriado

O'grady, S., Lane, H. (1996) The psychic distance paradox. Journal of International Business Studies, 27(2), 309-333.

http://dx.doi.org/10.1057/palgrave.jibs.8490137

O’ Sullivan, S.L., Appelbaum, S.H., Abikhzer, C. (2002) Expatriate management "Best practices" in Canadian MNC's: a multiple case study. Career Development International.

Pereira, M.A.F., Pimentel, F., Kato, H.T. (Out./Dez, 2005) Expatriação e estratégia internacional: o papel da família como fator de equilíbrio na adaptação do expatriado.. Revista de Administração Contemporânea, 9(4).

Sanchez, J.I., Spector, P.E., Cooper, C.L. (2000) Adapting to a boundaryless world: a developmental expatriate model. Academy of Management Executive, 14(2).

http://dx.doi.org/10.5465/AME.2000.3819309

Selvarajah, C.(Sept-1 Oct. 2003) Expatriate acculturation: linking predeparture experience to initial experience. In: Anais da Small Enterprise Association of Australia and New Zealand 16th Annual Conference, Ballarat, 28.

Swift, J. S. (1999) Cultural closeness as a facet of cultural affinity: a contribution to the theory of psychic distance. International Marketing Review, 16(3), 182-201.

http://dx.doi.org/10.1108/02651339910274684

Tung, R.L.(1981) Selection and training of personnel for overseas assignments. Columbia Journal of World Business, 68-78.

(1987).Expatriate assignments: Enhancing success and minimising failure. Academy of management executive, $117-126$.

Ulrich, D. (1998) Campeões de recursos humanos. São Paulo: Futura.

Winkelman, M.(1994) Cultural shock and adaptation. Journal of Counseling \& Development, 121126.

Revista Ibero-Americana de Estratégia - RIAE, São Paulo, v. 10, n. 3, p. 22-48, set./dez. 2011. 
Recebido: 21/09/2011

Aprovado: 15/11/2011

Revista Ibero-Americana de Estratégia - RIAE, São Paulo, v. 10, n. 3, p. 22-48, set./dez. 2011. 